Whitehead, J. C., Haab, T. C. and Huang, J. (2000) Measuring Recreation Benefits of Quality Improvements with Revealed and Stated Behavior Data, Resource and Energy Economics, 22(4): 339-354 (Oct 2000). Published by Elsevier (ISSN: 0928-7655).

\title{
Measuring recreation benefits of quality improvements with revealed and stated behavior data
}

\author{
John C. Whitehead, Timothy C. Haab, and Ju-Chin Huang
}

\begin{abstract}
We propose a combined revealed and stated behavior estimation method to measure recreation benefits of a fixed quality improvement that directly addresses the issues of variation in environmental quality beyond the observed range and new participation induced by higher quality. We survey a sample of the general population, including non-participants, to obtain stated preference data for trips based on a policy-relevant estuarine quality improvement. Panel recreation demand models that take into account new participants induced by the higher quality are estimated and used to derive total consumer surplus.
\end{abstract}




\section{INTRODUCTION}

The travel cost method (TCM) is a revealed behavior approach to measuring the economic benefits of outdoor recreation. Assuming that the travel and time costs of a recreation trip are the implicit price of the trip, demand functions are estimated between trip costs and trips. The traditional application of the TCM is to measure the consumer surplus of recreation sites and activities by calculating the consumer surplus of the site as the area below the demand function and above the implicit price (Freeman, 1993). Of more current policy relevance, however, is the valuation of quality improvements. Improvements in environmental quality, which may take the form of increases in catch rates, may lead to shifts in demand functions. The value of the improvements in quality is the area between the demand functions and above the implicit price. The benefits of quality improvement have been proven to be more difficult to measure with the traditional TCM because of problems in identifying the change in recreation demands from the quality change.

One approach to estimating the benefits of quality improvement is to pool data from recreation sites with different quality levels and estimate the effect of the quality variation on the number of trips taken [Smith and Desvousges, 1985] and [Bockstael et al., 1989]. Another approach that allows the valuation of site quality is the site choice, or random utility model (RUM; see [Kaoru et al., 1995] and [McConnell et al., 1995]). Other revealed behavior approaches to valuing recreation quality changes include the hedonic wage method (Clark and Kahn, 1989) and the hedonic TCM [Englin and Mendelsohn, 1991] and [Smith et al., 1991]. One limitation of these revealed preference approaches is the necessity of variation in quality across a number of sites. Also, the range of the observed variation may limit the policy relevance of the quality change. Forecasting recreation participation and trips beyond the range of historical variation can be problematic.

Another limitation to all of the revealed behavior approaches is the measure of environmental quality. Often, the available measures of environmental quality are objective. An assumption must be made that individuals' recreation choices are influenced by scientific measures of environmental quality such as dissolved oxygen, nitrogen and phosphorous loadings, or other environmental variables (i.e. [Smith and Desvousges, 1985] and [Clark and Kahn, 1989]). Further, these quality measures do not vary across individuals at the same recreation site, which makes valuation of environmental quality at a single site a difficult task due to no variation in quality. An alternative approach is to relate recreation choices to perceptions of the quality of the recreational experience (e.g., catch rates) that vary across the individuals, so that the valuation of quality of a single site is possible. However, indirect quality measures such as catch rates are based on a production process that depends, not only on the exogenous constraints imposed by environmental quality, but also on individual skills and experience, which results in an endogenous measure of quality.[2]

In contrast to revealed preference methods, the stated preference methods can be used to value quality at a single site by presenting hypothetical quality changes to survey respondents.[3] Responses to the hypothetical questions, or respondent-stated preferences, can be used to infer values for quality changes. The stated preference approach can focus on 
respondent willingness to pay [Boyle et al., 1993] and [Carson and Mitchell, 1993], site choice (Adamowicz et al., 1997), or the number of recreation trips taken under different quality scenarios [McConnell and Industrial Economics, 1986], [Ward, 1987] and [Loomis, 1993]. Stated preference methods also allow benefit estimation beyond the range of historical quality variation in revealed behavior data.

The stated preference approach has been found to be externally valid in various situations. For example, Loomis (1993) finds that intended and actual length of stay are not statistically different across a constant lake quality level. However, stated preference data may be prone to hypothetical bias [Diamond and Hausmann, 1994] and [Cummings et al., 1997]. One implication of research critical to stated preference data is that it can be "calibrated" by being combined with revealed behavior data. By combining data, the efficiency of benefit estimation can be improved and the consistency between the two types of data can be tested (Huang et al., 1997). Recent studies have demonstrated the benefits of combining revealed and stated behavior data for the valuation of environmental quality [Cameron, 1992], [Adamowicz et al., 1994], [Cameron et al., 1996], [Englin and Cameron, 1996] and [Layman et al., 1996]. However, these studies employ data on recreation participants only.[4] Excluding recreation non-participants, who become participants as the environmental quality is improved, may result in a downward bias of the total benefits of a quality improvement.

By combining revealed and stated behavior data, we propose an estimation method to measure recreation benefits of a quality improvement that takes into account the potential new recreation participation induced by the higher quality. The application is to the Albemarle and Pamlico Sounds in North Carolina. The method does not require variation of quality improvements across individuals or recreation sites. We survey a sample of the general population, including non-participants, to obtain revealed and stated preference data for trips based on a policyrelevant quality improvement. Panel recreation demand models that take into account new participants induced by the higher environmental quality are estimated and used to derive total benefits. The rest of the paper is organized as follows. In Section 2, we briefly describe the model to recover the benefit of a quality improvement as the change in consumer surplus. The model can include recreation participants, non-participants, and new participants induced by higher quality. We then discuss the data, empirical models and results from the application. Our conclusions follow.

\section{WELFARE MEASURES FOR A FIXED QUALITY IMPROVEMENT}

Consider an individual's utility function, $u\left(x_{j}, q_{j}, \boldsymbol{Z}\right)$, where $u(\cdot)$ is utility, $x_{j}$ is the seasonal number of trips to recreation site $j, j=1, \ldots, n, q_{j}$ is the quality of site $j$, and $\boldsymbol{Z}$ is a vector of all other goods. The individual faces a budget constraint, $y=Z+p_{j} x_{j}$, where $y$ is income, and $p_{j}$ is the travel and time costs of access, or implicit price, to site $j$. The quality of each recreation site is a non-priced good. Maximization of utility subject to the budget constraint yields a system of Marshallian demand functions, $x_{j}\left(p_{j}, q_{j}, y\right)$, with quantity-demanded decreasing in price, increasing in quality, and increasing (decreasing) in income for $x_{j}$ normal (inferior). 
The consumer surplus of trips to site $j$ is equal to the area beneath the demand function and above the implicit price, $\mathrm{CS}_{j}=\int_{p}{ }^{0 p c} X_{j}(\cdot) \mathrm{d} p_{j}$, where $p^{0}$ is the price to visit site $j$ and $p^{c}$ is the choke price that forces $x_{j}$ to go to zero. With an improvement in quality from $q$ to $q$, the demand function for recreation participants shifts to the right. The recreation benefits of the quality improvement can be measured as the change in CS that is the area between two demand curves above $p^{0}$ :

$$
\left.\Delta \mathrm{CS}=\int_{\mathrm{p}^{0}}^{\mathrm{p}^{\mathrm{c}^{r}}} \mathrm{x}^{\prime}\left(\cdot, \mathrm{q}^{\prime}\right) \mathrm{d} \mathrm{p}-\int_{\mathrm{p}^{0}}^{\mathrm{p}^{\mathrm{c}}} \mathrm{x}(\cdot, \mathrm{q})\right] \mathrm{d} \mathrm{p},
$$

where $p^{c \prime}$ and $p^{c}$ are the choke prices of the demands under quality $q^{\prime}$ and $q$, respectively. Individuals who face the choke price, $p^{c}$, at $q$ take zero trips and receive no consumer surplus benefits, but they would take trips at some $p<p^{c \prime}$ at $q^{\prime}$. These individuals are referred to as recreation non-participants. $\frac{5}{}$ That is, if the quality improvement is sufficiently large, some of the recreation non-participants will become participants. The inclusion of non-participants can have two effects. First, the higher rate of participation increases the total recreation benefits in the studied region even if the individual benefits stay the same. Second, the new participants under the higher quality may have an effect on the demand function so that $x^{\prime}\left(\cdot, q^{\prime}\right)$ does not necessarily have the same shape as $x(\cdot, q)$. For example, a quality improvement might cause demand for a recreation site to become more inelastic, with alternative sites becoming poor substitutes.

Fig. 1 illustrates an individual that reveals trips equal to $x$ at an average price of $p^{0}$ and current quality $(q)$. With a quality improvement $\left(q^{\prime}\right)$, the individuals states that he will take $x^{\prime}$ trips. $D(q)$ represents the individual's demand curve at current quality, and $D\left(q^{\prime}\right)$ and $D\left(q^{\prime}\right)^{*}$ represent two potential demand curves with improved quality. If we assume an improvement in quality results in a demand shift but no change in the elasticity of demand $\left(D\left(q^{\prime}\right)\right)$, then the change in total consumer surplus is represented by area a. However, if this individual's demand curve shifts and becomes more inelastic, then the expected demand curve becomes steeper $\left(D\left(q^{\prime}\right)^{\star}\right)$ and consumer surplus is measured by areas $a+b$.[6] For this individual, the consumer surplus measure derived by assuming no change in the elasticity of demand is biased downward by area $b$. To avoid the potential downward bias in recreation values, a more general model that includes new participants and allows more flexibility of the shift in demand in response to the higher environmental quality is needed. 


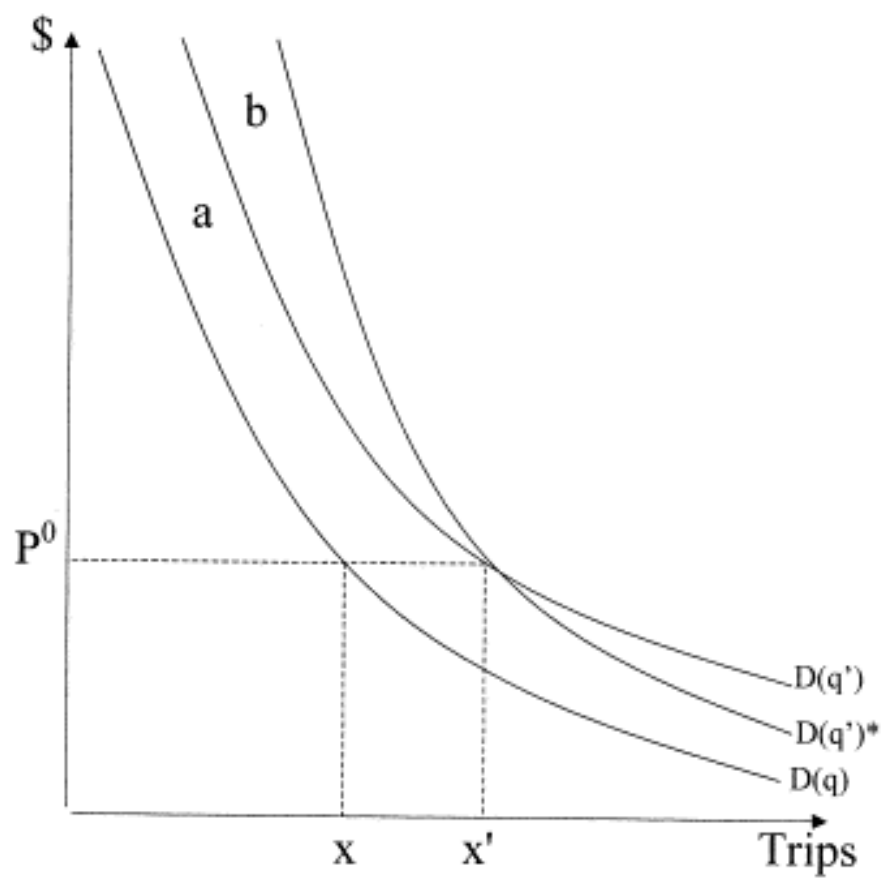

Fig. 1. Trip demand at current $(q)$ and improved quality $\left(q^{\prime}\right)$.

\section{DATA}

The data for this study are from a 1995 telephone survey of eastern North Carolina households that proposed a management plan to restore Albemarle and Pamlico Sound resources to their pre-1981 condition. The survey used a random digit dialing sampling scheme. The 41 counties surveyed are roughly those east of Interstate 95 in North Carolina. Of the households that were contacted, 1021 completed the questionnaire for an overall response rate of $71 \%$.

Approximately $75 \%$ of the completed questionnaires contains all the information necessary for this study, which amounts to 765 observations.

In the survey, a hypothetical scenario that contained a policy to control agricultural and commercial fishing practices that pollute water and damage wildlife habitat was presented to respondents.[7] The policy is described as able to restore Albemarle and Pamlico Sound resources and increase fish catches by $60 \%$ and open $25 \%$ more shellfish beds. There are two versions of the telephone survey. Version 1 focused on the Pamlico Sound and Version 2 focused on both the Albemarle and Pamlico Sounds. The main difference in the two versions is the insertion of "Albemarle and" before Pamlico in all questions and the addition of the plural to Sound(s). We considered a broad range of recreational activities in order to increase the sample of recreation participants. These activities include fishing, hunting, swimming, boating, skiing, windsurfing, birdwatching, and camping.

Respondents were asked about their current recreation participation (PART_1) and intensity (TRIPS_1), and their expected recreation participation (PART_2) and intensity (TRIPS_2) with 
current quality levels. Then, following a description of the proposed policy that would improve quality, respondents were asked about their participation (PART_3) and the number of trips they would take with the improvement (TRIPS_3). Hence, a panel data set, including both revealed (TRIPS_1) and stated (TRIPS_2 and TRIPS_3) behavior information for each respondent, is constructed. The data are summarized in Table 1. The average household income is US $\$ 32,500$, which is representative of the population income level.

Table 1

Data summary

\begin{tabular}{lccl}
\hline Variable & Mean & SD & Description \\
\hline PART_1 & 0.21 & 0.41 & Revealed participation with current quality \\
PART_2 & 0.32 & 0.47 & Stated participation with current quality \\
PART_3 & 0.43 & 0.50 & Stated participation with improved quality \\
TRIPS_1 & 2.39 & 18.90 & Revealed trips with current quality \\
TRIPS_2 & 3.38 & 22.30 & Stated trips with current quality \\
TRIPS_3 & 3.46 & 18.08 & Stated trips with improved quality \\
INCOME & 32.54 & 21.45 & Income (in thousands) \\
TCP & 88.90 & 58.60 & Trip costs to Pamlico Sound \\
TCF & 124.80 & 76.00 & Trip costs to Cape Fear \\
PAMLICO & 0.54 & 0.50 & 1 if Pamlico version; 0, otherwise \\
Sample & 765 & & \\
\hline
\end{tabular}

Twenty-one percent of the sample participated in recreation at the Sounds (state of the world $t=1$ ). Thirty-two percent of the sample states that they will participate in outdoor recreation during the next 12 months with the same quality level $(t=2)$. The difference in participation between $t=1$ and $t=2$ is significant at the $p=0.001$ level $\left(x^{2}=21.46[1 \mathrm{df}]\right)$. With the improvement in quality, participation increases to $43 \%(t=3)$. The difference in participation between $t=1$ and $t=3$ is significant at the $p=0.001$ level $\left(x^{2}=84.38[1 \mathrm{df}]\right)$. The difference in participation between $t=2$ and $t=3$ is significant at the $p=0.001$ level $\left(x^{2}=21.59[1 \mathrm{df}]\right)$.

The average number of trips taken during the 12 months prior to the survey is $2.39(t=1)$. Respondents state that they will take about one more trip during the next 12 months with the same quality level $(t=2)$. The Wilcoxon rank-sum test (Freund and Walpole, 1980) is used to test the difference in the mean number of trips due to the non-normality of the trip data and the influence of outliers on differences in means tests. The rank-sum test indicates that the number of revealed trips and stated trips taken with current quality is significantly different at the $p=0.0001$ level $(z=-4.34)$.

One possible explanation for this difference is that respondents may believe that expected future income (in $t=2$ ) will be higher than current income $(t=1)$. If trips are normal goods, then expected recreation trips will also be higher.[8] Another potential reason is hypothetical bias. Stated behavior may be different than revealed behavior under identical circumstances due to good intentions. When unexpected constraints materialize, the full extent of the good intentions may not be realized. This interpretation fits the result of Bockstael et al. (1988, p. 45-46), who 
find that intended trips for the rest of the beach season overstate actual trips realized after the season. The beach season is a period of time during which income would not be expected to vary.

With the improvement in quality, the stated number of trips increases to $3.46(t=3)$. The ranksum test indicates that the number of revealed trips with current quality $(t=1)$ and stated trips with improved quality $(t=3)$ is significantly different at the $p=0.0001$ level $(z=-8.62)$. The mean difference in the number of trips (TRIPS_3-TRIPS_1=1.07) between these scenarios understates the increased number of trips with quality due to the influence of a single outlier. Removal of this outlier increases the mean number of increased trips to 1.55 .

The rank-sum test indicates that the number of stated trips with current quality $(t=2)$ and stated trips with improved quality $(t=3)$ is significantly different at the $p=0.0001$ level $(z=-4.41)$. Again, the mean difference in the number of trips (TRIPS_3-TRIPS_2=0.08) between these scenarios understates the increased number of trips with quality due to the influence of a single outlier. Removal of this outlier increases the mean number of increased trips to 0.56.[9] The Pamlico travel cost (TCP) variable (own-price) is constructed as follows. For respondents living west of the Pamlico or Neuse Rivers, the distance was calculated as the minimum distance from the respondent's county population center to the towns of Washington on the Pamlico River or New Bern on the Neuse River. If the respondent lived north or south of the Rivers, the distance was calculated as distance from the county population center to the nearest boat ramp on the Sound. The travel cost used is US $\$ 0.20 /$ mile, average miles per hour is 50 , and the opportunity cost of travel time is valued at the wage rate (wage=INCOME/2080). We assume that all trips are day trips and that the cost of on-site time is zero. The travel costs to the substitute recreation site (Cape Fear, NC[10]), the cross-price (TCF), was constructed similarly. The average own-price is US\$89 and the average cross-price is US\$125.

\section{EMPIRICAL MODELS}

To fully account for the effects of quality improvement on the stated and revealed recreation demands, two important issues must be incorporated into the empirical models. First, new participants must be included in the estimation of recreation demands. Second, the variation between revealed and stated data must be tested and treated in the empirical models. We propose to pool all three trip responses (TRIPS_t, $t=1,2,3$ ) together and estimate a joint recreation demand model. The random effects Poisson model with dummy variables (fixed time effect) is employed to take into account the heterogeneity among individuals and the potential structural changes in demand in different states. The Poisson regression is used to study count data, in our case the trips to a recreation site in a season. Assume that $x_{i t}$, the number of trips taken by the individual $i$ in a particular trip scenario $t$, is drawn from a Poisson distribution with mean $\mu_{i t}$ : 
(2)

$\operatorname{Prob}\left(\mathrm{X}_{\mathrm{it}}=\mathrm{x}_{\mathrm{it}}\right)=\frac{\mathrm{e}^{-\mu_{\mathrm{it}} \mu_{\mathrm{it}}^{\mathrm{x}_{\mathrm{it}}}}}{\mathrm{x}_{\mathrm{it}} !} \quad \mathrm{x}_{\mathrm{it}}=0,1,2, \ldots$

The mean $\mu_{i t}$ depends on the explanatory variables (defined in Table 1) for $x_{i t}$ and individual heterogeneity:

$$
\ln \mu_{\mathrm{it}}=\ln \lambda_{\mathrm{it}}+\mathrm{u}_{\mathrm{i}}=\alpha_{\mathrm{t}}+\beta_{\mathrm{t}} \mathrm{TCP}_{\mathrm{it}}+\delta_{\mathrm{t}} \mathrm{TCF}_{\mathrm{it}}+\phi_{\mathrm{t}} \mathrm{INCOME}_{\mathrm{it}}+\varphi_{\mathrm{t}} \mathrm{PAMLICO}_{\mathrm{it}}+\mathrm{u}_{\mathrm{i}} \text {, }
$$

where $t=1,2,3$ and $u_{i}$ is a random effect for group $i . u_{i}$ allows trip variation across individuals that cannot be explained by prices and income. In addition, it also indicates the possible correlation in responses to different trip scenarios for the same individual. The distribution of trips $x_{i t}$ conditioned on $u_{i}$ is Poisson with conditional mean and variance $\mu_{i t}$. If $\exp \left(u_{i}\right)$ is assumed to follow a gamma distribution, then the unconditional number of trips, $x_{i t}$, follows a negative binomial distribution (Hausman et al., 1984). To combine data from all three trip scenarios and to account for the potential structural change in trip demand across scenarios, we create two dummy variables: D_2 $=1$ if $t=2$ and D_2 $=0$, otherwise; $\_\_3=1$ if $t=3$ and $D \_3=0$, otherwise. A general recreation demand model that allows us to pool the data from all three trip scenarios is derived by incorporating these two dummy variables into the mean $\mu_{i t}$ :

$$
\begin{aligned}
\ln \mu_{i t}= & \ln \lambda_{i t}+u_{i}=\alpha_{1}+\beta_{1} \mathrm{TCP}_{i t}+\delta_{1} \mathrm{TCF}_{i t}+\phi_{1} \mathrm{INCOME}_{i t}+\varphi_{1} \mathrm{PAMLICO}_{i t}+a_{2} \mathrm{D} \_2+b_{2} \mathrm{D} \_2 \mathrm{TCP}_{i t}+c_{2} \mathrm{D} \_2 \mathrm{TCF}_{i t}+d_{2} \mathrm{D}_{2} 2 \mathrm{INCOME}_{i t} \\
& +a_{3} \mathrm{D} \_3+b_{3} \mathrm{D}_{3} 3 \mathrm{TCP}_{i t}+c_{3} \mathrm{D} \_3 \mathrm{TCF}_{i t}+d_{3} \mathrm{D}_{2} 3 \mathrm{INCOME}_{i t}+u_{i t}
\end{aligned}
$$

The dummy variables, D_2 and D_3, allow differences in logged-demand intercepts across three trip scenarios. Differences in elasticities are represented by interacting the dummy variable with the own-price (D_t $t \mathrm{TCP})$, cross-price (D_t $t \mathrm{TCF}$ ) and income (D_t INCOME), $t=2,3$. As seen in Fig. 1, to measure the change in consumer surplus, the potential structural changes in recreation demand induced by the quality improvement must be identified first. Based on the model in Eq. 4, there are several testable hypotheses. If there is no structural change across three trip scenarios, then $a_{t}=b_{t}=c_{t}=d_{t}=0, t=2$, 3. If there is no structural change before and after the quality improvement, then $a_{3}=b_{3}=c_{3}=d_{3}=0$. If there is no difference between the revealed recreation demand for this season and the stated recreation demand for the next season, then $a_{2}=b_{2}=c_{2}=d_{2}=0$. It is also possible that the structural changes in demand are "parallel" shifts with constant elasticities. In that case, $a_{t} \neq 0$ and $b_{t}=c_{t}=d_{t}=0, t=2,3$.

The mean demand specification of Eq. 4 is semi-log. Both choke prices (before and after the quality change) on the expected demand function are infinite. This does not imply that individuals cannot be priced out of the market for recreation trips. The semi-log specification simply guarantees that the expected quantity demanded for recreation trips will be positive. An individual's expected demand asymptotically approaches zero as the price increases. An individual's seasonal recreational value of a quality improvement is therefore: 
(5)

$$
\Delta \mathrm{CS}=\frac{\mathrm{x}^{\prime}}{\beta^{\prime}}-\frac{\mathrm{x}}{\beta},
$$

where $x^{\prime}$ is the number of trips taken under higher quality and $\beta^{\prime}$ is the coefficient of $p$ in the new demand function with $q^{\prime}$. This measure of consumer surplus takes into account the new participants induced by the higher environmental quality because $x^{\prime}$ includes new participants and is allowed to be structurally different from $x$. If the coefficient of price remains the same after a quality improvement, the benefit measure in Eq. 5 can be simplified to $\Delta C S=\left(x^{\prime}-x\right) / \beta$. The consumer surplus and elasticity estimates are constructed as non-linear functions of parameter estimates. We use the predicted number of trips in the consumer surplus calculations assuming that there is measurement error in the dependent variable (Bockstael and Strand, 1987). The independent variables are evaluated at their means for these calculations.[11]

\section{ESTIMATION RESULTS}

Revealed and stated behavior data can only be combined and jointly estimated if the null hypothesis of equality of coefficient vectors cannot be rejected. Table 2 presents the random effects Poisson estimation results. We first estimate the most general model (Model 1 in Table 2), in which intercepts and slopes of the logged demand are allowed to vary across revealed and stated behavior versions.[12] The own-price and cross-price coefficients have the expected signs and are significantly different from zero at the 0.01 level. The income coefficient is significantly greater than zero at the 0.05 level, indicating that trips are normal goods. The Pamlico version dummy variable is negative and significantly different from zero. The random effects parameter $(u)$ is significant, indicating that there is common variation in individual responses across response formats; independent Poisson models for the different response formats are inappropriate. 
Table 2

Random effects Poisson model

\begin{tabular}{|c|c|c|c|c|}
\hline \multirow[t]{2}{*}{ Variable } & \multicolumn{2}{|l|}{ Model 1} & \multicolumn{2}{|l|}{ Model 2} \\
\hline & Coefficient & $t$ ratio & Coefficient & $t$ ratio \\
\hline Constant & -0.0682 & -0.35 & -0.0682 & -0.46 \\
\hline $\mathrm{TCP}$ & -0.0183 & -7.76 & -0.0156 & -9.42 \\
\hline TCF & 0.0120 & 8.75 & 0.0123 & 12.92 \\
\hline INCOME & 0.0153 & 1.91 & 0.0073 & 1.32 \\
\hline \multirow[t]{2}{*}{ PAMLICO } & -0.2033 & -2.21 & -0.2004 & -2.07 \\
\hline & \multicolumn{4}{|c|}{ Stated behavior with current quality } \\
\hline D_2 & 0.4114 & 1.39 & 0.4221 & 4.73 \\
\hline D_2 TCP & 0.0051 & 1.63 & & \\
\hline D_2 TCF & 0.0004 & 0.24 & & \\
\hline \multirow[t]{2}{*}{ D_2 INCOME } & -0.0146 & -1.35 & & \\
\hline & \multicolumn{4}{|c|}{ Stated behavior with improved quality } \\
\hline D_3 & 0.9888 & 3.13 & 0.9872 & 3.43 \\
\hline D_3 TCP & 0.0065 & 2.04 & 0.0038 & 1.39 \\
\hline D_3 TCF & -0.0036 & -1.68 & -0.0038 & -2.07 \\
\hline D_3 INCOME & -0.0135 & -1.21 & -0.0056 & -0.58 \\
\hline$u$ & 6.49 & 22.03 & 6.50 & 22.05 \\
\hline Log-likelihood & -3411.23 & & -3412.38 & \\
\hline Sample & 2295 & (three periods and 765 cases) & & \\
\hline
\end{tabular}

We first test whether the revealed and stated behavior models with the same quality levels represent the same underlying behavior $\left(\mathrm{H}_{0}: a_{2}=b_{2}=c_{2}=d_{2}=0\right)$. We find that, individually, there is no statistically significant difference in any of the intercept, own-price, cross-price, or income coefficients between revealed and stated trips with current quality. However, the coefficient vector associated with $\mathrm{D} \_2,\left[a_{2}, b_{2}, c_{2}, d_{2}\right]$ is jointly statistically different from zero $\left(x^{2}=16.90[4\right.$ $d f]$ ), indicating that the revealed and stated behavior data with current quality represent different recreation demand models.

In the comparison of revealed trips with current quality and stated trips with improved quality, the quality improvement dummy variable (the intercept shifter D_3) is significantly different from zero at the 0.01 level. This result indicates that the quality improvement will lead to an increase in the number of trips taken, holding other variables constant. The coefficient on the interaction between D_3 and the own-price is positive and significantly different from zero at the 0.05 level. The coefficient on the interaction between D_3 and the cross-price is significantly different from zero at the 0.10 level. The coefficient on the interaction between the quality improvement dummy variable and income is not significantly different from zero. The results indicate a shift as well as a change in elasticities of the recreation demand as the environmental quality is improved.

We next test for equality between the stated behavior coefficient vectors with and without the quality change $\left(\mathrm{H}_{0}: \mathrm{a}_{2}=a_{3}, b_{2}=b_{3}, c_{2}=c_{3}, d_{2}=d_{3}\right)$, and find that there is no statistically significant difference between these vectors of coefficients $\left(x^{2}=5.67[4 d f]\right)$. Therefore, we reject the 
hypothesis that the revealed and stated behavior data with current quality represent the same underlying behavior in the most general model. Since the most general model is potentially over-identified, it may contain irrelevant variables to inflate the standard errors of the variables that actually belong in the model. This could lead to the finding of no statistically significant difference in coefficient vectors. We conduct a joint significance test for the stated behavior with current quality interaction variables $\left(\mathrm{H}_{0}: b_{2}=c_{2}=d_{2}=0\right)$. This test indicates that the elasticities are not significantly different from the revealed behavior data elasticity coefficients $\left(x^{2}=2.69[3 d f]\right)$.

Based on this test result, we next estimate a model without interaction between D_2 and the other explanatory variables (Model 2 in Table 2), which still allows a shift in demand from the revealed to stated behavior data with current quality but restricts the elasticities to be equal. The stated behavior with improved quality demand is allowed to shift and change shape with the interaction variables. This more parsimonious specification yields statistically significant coefficients on the stated behavior intercept shift variables. We conclude that the revealed and stated behavior data can be combined after the hypothetical bias is calibrated. In other words, the revealed and stated behavior data represent the same underlying behavior at current quality levels after accounting for the shift in stated behavior demand. The stated behavior intercepts are significantly different from each other at the 0.10 level $\left(\mathrm{H}_{0}: \mathrm{a}_{2}=\mathrm{a}_{3}, x^{2}=3.75[1 \mathrm{df}]\right)$. The interactions between $D_{-} 3$ and the explanatory variables are jointly statistically significant at the 0.10 level $\left(\mathrm{H}_{0}: b_{3}=c_{3}=d_{3}=0, X^{2}=6.76[3 d f]\right)$. Again, we find structural changes in recreation demand once the environmental quality is improved.

The own-price, cross-price, and income elasticities from Model 2 are presented in Table 3. The own-price and cross-price elasticities are significantly different from zero. The own-price elasticities are greater than one (in absolute value). Demand is more price inelastic with the quality improvement but the difference is not statistically significant. The cross-price elasticity estimates are significantly different at the 0.05 level. With the quality improvement, the alternative recreation site becomes a less attractive substitute. Differences in the income elasticity estimates are not significantly different from zero.

Table 3

Elasticity estimates

\begin{tabular}{lllr}
\hline Elasticity & Coefficient & SE & $t$ ratio \\
\hline Own-price & Current quality & & \\
Cross-price & -1.386 & 0.147 & -9.42 \\
Income & 1.533 & 0.119 & 12.92 \\
& 0.239 & 0.181 & 1.32 \\
Own-price & Improved quality & & \\
Cross-price & -1.046 & 0.209 & -5.01 \\
Income & 1.058 & 0.192 & 5.50 \\
\hline
\end{tabular}


Consumer surplus estimates are reported in Table 4. The baseline number of trips with current quality is equal to the predicted number of revealed behavior trips calibrated by the shift variable (D_2) in the stated behavior model with current quality. Trips with improved quality are predicted using the revealed behavior trips calibrated by the stated behavior with improved quality coefficients. The predicted trips are 1.88 and 2.49 for current quality and improved quality, respectively. The difference in predicted trips is statistically significant at the 0.10 level $(t=1.87)$. The consumer surplus per trip estimate with current quality is US\$64 and with improved quality is US\$85. The US\$21 difference is not statistically significant at the 0.10 level $(t=1.18)$. Multiplying the consumer surplus per trip estimate from the revealed behavior model by predicted trips leads to consumer surplus per season estimates of US\$121 and US\$155 for current and improved quality, respectively. The US\$34 difference in consumer surplus per season due to the quality improvement is statistically significant at the 0.10 level $(t=1.88)$.

Table 4

Consumer surplus estimates

\begin{tabular}{lccc}
\hline Consumer surplus & Coefficient (US\$) & SE & $t$ ratio \\
\hline & Current quality & & \\
Per trip & 64.14 & 6.09 & 9.42 \\
Per season & 120.53 & 17.14 & 7.03 \\
& & & \\
Per trip & Improved quality & 16.96 & 5.01 \\
Per season & 84.99 & 22.27 & 6.94 \\
\hline
\end{tabular}

Finally, we estimate a random effects panel model with current participants only $(n=163) . \underline{13}$ Both stated behavior demands (TRIPS_2 and TRIPS_3) are significantly higher than the revealed behavior demand (TRIPS_1) but not significantly different from each other. The consumer surplus per trip is US\$105. In this application, excluding non-participants (or new participants with quality improvement) would overstate consumer surplus per trip and fail to identify the change in consumer surplus per season due to the quality change.

\section{CONCLUSIONS}

In this paper, we show how stated preference methods can be used to value quality changes at a single site without imposing the assumption that individuals respond to objective measures of site quality. The stated preference method allows estimation of consumer surplus beyond the range of historical quality variation in revealed behavior data. We argue that new recreation participation induced by higher quality should be included in estimating the changes in recreation demands. It is shown that with a quality improvement, there is a potential structural change in recreation demand due to both the new participants and variations in revealed and 
stated data. Models that fail to take into account the structural changes in demands for different quality levels can result in bias in consumer surplus measures.

We find that combining revealed and stated trips can detect changes in the demand for recreation due to changes in perceived quality. Using revealed and stated trips with current quality as the baseline, we find significant changes in trips, consumer surplus per season, and the cross-price elasticity of demand due to the improvement in quality. These changes can be attributed to a stated increase in the number of trips taken with improved quality and a structural change in the shape of the demand curve due to an influx of new participants when quality is improved.

A summation of consumer surplus per season estimates over households in the 41 county eastern North Carolina region yields an estimate of the annual aggregate consumer surplus. Considering that there are about 800,000 households in the 41 county survey regions, aggregate consumer surplus with current quality is about US\$88 million (1995 dollars) for the Pamlico and US\$107 million for the Albemarle and Pamlico Sounds combined. A quality improvement to pre-1981 levels would lead to aggregate consumer surplus of US\$113 million and US\$138 million (1995) for the Pamlico and Albemarle-Pamlico Sounds. The change in consumer surplus from the quality improvement would be about US\$25 million for the Pamlico Sound and US\$31 million for the Albemarle and Pamlico Sounds. These estimates should be considered lower bounds since recreation participation in the Albemarle and Pamlico Sounds for residents outside the 41 county regions is substantial. This estimate could be compared to an estimate of the costs of this policy to determine the net benefits of the policy to society.

Future research with revealed and stated behavior data should explore variations in the quality change variable. Our study is limited in that we examine a fixed quality change. Also, our study is limited in that the destination site is large with an own-price measured with perhaps substantial error and the substitute site is assumed by the researcher and not determined through actual trip visitation patterns. Future research should explore the sensitivity of our results to these assumptions.

We find evidence that stated behavior models may be prone to hypothetical bias. Comparing the consumer surplus from the revealed behavior model (with current quality) with the stated behavior model with improved quality may overestimate consumer surplus. We calibrated our stated behavior model by assuming that the hypothetical bias is constant between the stated behavior models with current and improved quality. In this way, we avoid potentially overestimating the change in consumer surplus. The estimated change in consumer surplus could still be biased in either direction if the change in stated behavior is not equal to the change in revealed behavior. Future research should investigate the validity of this assumption. One way is to collect data using a panel survey of consumers who are faced with actual and predictable changes in quality (e.g., reservoir levels). A comparison of stated behavioral change before the quality change with the revealed behavioral change after the quality change would provide some evidence about the validity of our assumption. 


\section{ACKNOWLEDGEMENTS}

The authors thank two anonymous referees for many insightful comments. This paper has also benefited from presentations at Colorado State University, East Carolina University, and the Southern Economic Association Meetings. The data for this paper were collected with funding from the East Carolina University Department of Economics and are available at the website $<$ http://personal.ecu.edu/whiteheadj/data/ree99006/>.

\section{NOTES}

$1 \mathrm{New}$ affiliation as of August 2000. Formerly: Department of Economics, East Carolina University, USA.

2 See Kaoru et al. (1995) and McConnell et al. (1995) for a solution to the endogeneity problem.

3 Using perceptions of quality has limitations, especially when conducting policy analysis. See Adamowicz et al. (1997) for a discussion of this issue.

4 Cameron et al. (1996) survey non-users but the hypothetical quality improvement is not sufficient to induce increased participation.

5 There is also, conceivably, a third group of individuals who would not participate in recreation at any $p$ or $q$. These individuals, market non-participants, do not participate in the recreation market for health or preference reasons and do not receive any consumer surplus [Grogger and Carson, 1991] and [Haab and McConnell, 1996].

6 It should be noted that Fig. 1 is illustrated for one individual with known demand. When demand is estimated for a sample of individuals, the estimated demand curve represents an average of the sample demands and as such, the predicted consumer surplus for each individual can be biased up or down. It is expected that the average bias will be downward.

7 See the Appendix at the website <http://personal.ecu.edu/whiteheadj/data/ree99006/> for the revealed and stated behavior questions.

8 We did not ask respondents to assume that future income is constant. For many respondents, future income may be increasing and a counterfactual assumption may further complicate the process of requesting hypothetical behavior data.

9 The results for differences in recreation participation and trips are available at the website <http://personal.ecu.edu/whiteheadj/data/ree99006/>.

10 Cape Fear, NC was chosen as the substitute site. Respondents were not asked their alternative recreation destinations so a proxy cross-price was determined. The (Albemarle and) Pamlico Sound(s) is a large destination site accounting for most of the northern coast of North Carolina. Cape Fear is at the southernmost point of the southern North Carolina coast. Second, 
several cross-price variables were attempted in pretest models, with TCF performing the best in terms of statistical significance.

11 The standard errors for the consumer surplus and elasticity estimates are evaluated at the means of the variables and computed using the Delta Method as the square root of the variance: var $=\boldsymbol{X}^{\prime} \boldsymbol{\Sigma}^{-1} \boldsymbol{X}$ where $\boldsymbol{X}$ is the vector of mean values and $\boldsymbol{\Sigma}$ is the variance-covariance matrix (Greene, 1997). All estimations are conducted with LIMDEP 7.0 (Greene, 1995).

12 We use the stated behavior demand as the baseline in our models. The wording of the hypothetical questions allows the respondent to assume that TRIPS_2 and TRIPS_3 occur during the next 12 months.

13 The estimation results with current participants only can be found at the website, <http://personal.ecu.edu/whiteheadj/data/ree99006>.

\section{REFERENCES}

Adamowicz, W., Louviere, J., Williams, M., 1994. Combining revealed and stated preference methods for valuing environmental attributes. Journal of Environmental Economics and Management 26, 271-292.

Adamowicz, W., Swait, J., Boxall, P., Louviere, J., Williams, M., 1997. Perceptions versus objective measures of environmental quality in combined revealed and stated preference models of environmental valuation. Journal of Environmental Economics and Management 32, 65-84.

Bockstael, N.E., McConnell, K.E., Strand, I.E., 1988. Benefits from improvements in Chesapeake Bay water quality, Benefit Analysis Using Indirect or Imputed Market Methods, Vol. II. Report to the U.S. Environmental Protection Agency.

Bockstael, N.E., McConnell, K.E., Strand, I.E., 1989. Measuring the benefits of improvements in water quality: the Chesapeake Bay. Marine Resource Economics 6, 1-18.

Bockstael, N.E., Strand, I.E. Jr., 1987. The effect of common sources of regression error on benefit estimates. Land Economics 63, 11-20.

Boyle, K.J., Welsh, M.P., Bishop, R.C., 1993. The role of question order and respondent experience in contingent valuation studies. Journal of Environmental Economics and Management 25, S80-S99.

Cameron, T.A., 1992. Combining contingent valuation and travel cost data for the valuation of non-market goods. Land Economics 68, 302-317.

Cameron, T.A., Shaw, W.D., Ragland, S.E., Mac Callaway, J., Keefe, S., 1996. Using actual and contingent behavior data with differing levels of time aggregation to model recreation demand. Journal of Agricultural and Resource Economics 21, 130-149. 
Carson, R.T., Mitchell, R.C., 1993. The value of clean water: the public's willingness to pay for boatable, fishable, and swimmable quality water. Water Resources Research 29, 2445-2454.

Clark, D.E., Kahn, J.R., 1989. The two-stage hedonic wage approach: a methodology for the evaluation of environmental amenities. Journal of Environmental Economics and Management 16, 106-120.

Cummings, R.G., Elliott, S., Harrison, G.W., Murphy, J., 1997. Are hypothetical referenda incentive compatible? Journal of Political Economy 105, 609-621.

Diamond, P.A., Hausman, J.A., 1994. Contingent valuation: is some number better than no number? Journal of Economic Perspective 8, 45-64.

Englin, J., Cameron, T.A., 1996. Augmenting travel cost models with contingent behavior data. Environmental and Resource Economics 7, 133-147.

Englin, J., Mendelsohn, R., 1991. A hedonic travel cost analysis for valuation of multiple components of site quality: the recreation value of forest management. Journal of Environmental Economics and Management 21, 275-290.

Freeman, A.M. III, 1993. The Measurement of Environmental and Resource Values: Theory and Methods. Resources for the Future, Washington, DC.

Greene, W.H., 1995. LIMDEP Version 7.0: User's Manual. Econometric Software, Bellport, NY. Greene, W.H., 1997. Econometric Analysis. 3rd edn. Prentice-Hall, Upper Saddle River, NJ.

Grogger, J.T., Carson, R.T., 1991. Models for truncated counts. Journal of Applied Econometrics 6, 225-238.

Haab, T.C., McConnell, K.E., 1996. Count data models and the problem of zeros in recreation demand analysis. American Journal of Agricultural Economics 78, 89-102.

Hausman, J., Hall, B., Griliches, Z., 1984. Econometric models for count data with an application to the patents - R\&D relationship. Econometrica 52, 909-938.

Huang, J.C., Haab, T.C., Whitehead, J.C., 1997. Willingness to pay for quality improvements: should revealed and stated preference data be combined? Journal of Environmental Economics and Management 34, 240-255.

Kaoru, Y., Smith, V.K., Liu, J.L., 1995. Using random utility models to estimate the recreational value of estuarine resources. American Journal of Agricultural Economics 77, 141-151.

Layman, R.C., Boyce, J.R., Criddle, K., 1996. Economic valuation of the Chinook Salmon Sport Fishery of the Gulkana River, Alaska, under current and alternate management plans. Land Economics 72, 113-128.

Loomis, J.B., 1993. An investigation into the reliability of intended visitation behavior. Environmental and Resource Economics 3, 183-191. 
Industrial Economics, McConnell, K.E., 1986. The Damages to Recreational activities from PCBs in New Bedford Harbor. Ocean Assessment Division, National Oceanic and Atmospheric Administration, Rockville, MD.

McConnell, K.E., Strand, I.E., Blake-Hedges, L., 1995. Random utility models of recreational fishing: catching fish using a Poisson process. Marine Resource Economics 10, 247-262.

Smith, V.K., Desvousges, W.H., 1985. The generalized travel cost model and water quality benefits: a reconsideration. Southern Economic Journal 52, 371-381.

Smith, V.K., Palmquist, R.B., Jakus, P., 1991. Combining Farrell frontier and hedonic travel cost models for valuing estuarine quality. Review of Economics and Statistics 73, 694-699.

Ward, F., 1987. Economics of water allocation to instream uses in a fully appropriated river basin: evidence from a New Mexico wild river. Water Resources Research 23, 381-392. 